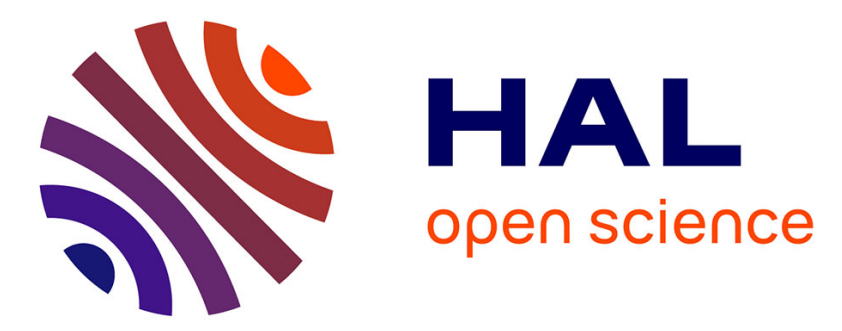

\title{
Effects of functionalized halloysite on morphology and properties of polyamide-11/SEBS-g-MA blends
}

Mohamed Sahnoune, Aurélie Taguet, Belkacem Otazaghine, Mustapha Kaci, José-Marie Lopez-Cuesta

\section{To cite this version:}

Mohamed Sahnoune, Aurélie Taguet, Belkacem Otazaghine, Mustapha Kaci, José-Marie LopezCuesta. Effects of functionalized halloysite on morphology and properties of polyamide-11/SEBSg-MA blends. European Polymer Journal, 2017, 90, pp.418-430. 10.1016/j.eurpolymj.2017.03.008 . hal-02892647

\section{HAL Id: hal-02892647 \\ https://hal.science/hal-02892647}

Submitted on 15 Dec 2020

HAL is a multi-disciplinary open access archive for the deposit and dissemination of scientific research documents, whether they are published or not. The documents may come from teaching and research institutions in France or abroad, or from public or private research centers.
L'archive ouverte pluridisciplinaire $\mathbf{H A L}$, est destinée au dépôt et à la diffusion de documents scientifiques de niveau recherche, publiés ou non, émanant des établissements d'enseignement et de recherche français ou étrangers, des laboratoires publics ou privés. 


\title{
Effects of functionalized halloysite on morphology and properties of polyamide-11/SEBS-g-MA blends
}

\author{
Mohamed Sahnoune ${ }^{\mathrm{a}, \mathrm{b}}$, Aurélie Taguet ${ }^{\mathrm{b}, *}$, Belkacem Otazaghine ${ }^{\mathrm{b}}$, Mustapha Kaci ${ }^{\mathrm{a}}$, \\ José-Marie Lopez-Cuesta ${ }^{\mathrm{b}}$ \\ a Laboratoire des Matériaux Polymères Avancés (LMPA), Université de Bejaia, 06000, Algeria \\ ${ }^{\mathrm{b}}$ Centre des Matériaux des Mines d'Alès (C2MA), Ecole des Mines d'Alès, 6 avenue de Clavières, 30319 Alès cedex, France
}

\section{A B S T R A C T}

Halloysite nanotubes (HNTs) were functionalized by grafting styrene-ethylene-butylene-styrene (SEBS) copolymer chains after a two-step modification procedure. Fourier transform infrared spectroscopy (FTIR), thermal gravimetric analysis (TGA) and pyrolysis-gas chromatography-mass spectrometry (Py-GC/MS) were used to determine the grafting rate. Then, raw and functionalized halloysites were incorporated into polyamide-11(PA11)/ styrene-ethylene-butylene-styrene grafted maleic anhydride (SEBS-g-MA) blends $(85 / 15 \mathrm{w} / \mathrm{w})$. Scanning electron microscopy (SEM) and transmission electron microscopy (TEM) micrographs show a good dispersion of both halloysites particles and SEBS-g-MA nodules in the PA11 matrix. In the case of functionalized halloysite, the presence of HNTs bundles surrounded with fine SEBS-g-MA nodules is observed. Atomic force microscopy (AFM) also highlighted the different blends morphologies. Incorporation of functionalized halloysite leads to an improvement of the thermal properties without affecting the PA11 crystallization. Moreover, mechanical performance, especially toughness, was highly improved in the presence of functionalized halloysite due to a good stress transfer from the matrix to the modified halloysite agglomerates surrounded by SEBS-g-MA.

\section{Keywords:}

Polyamide-11

Nanocomposites

Halloysite

Grafting

Polymer blends

\section{Introduction}

Polyamide-11 (PA11) is an interesting commercial aliphatic polyamide. PA11 is biocompatible and exhibits excellent characteristics such as good oil resistance and has the advantage to be less hydrophilic than the commonly used polyamide- 6 and $6,6[1,2]$. Therefore, PA11 is widely used as an engineering polymer in a large range of industrial fields from automotive to offshore applications including food packaging. However, like all the polyamides, PA11 is rather brittle and notch sensitive at high strain rates and/or at low temperatures [3]. Thus, incorporation of an elastomeric phase like styrene-ethylene-butylene-styrene (SEBS) [4], ethylene-propylene-rubber (EPR) [5] or ethylene propylene diene monomer (EPDM) [6] can be a good way to obtain polyamides with improved toughness. Due to their low compatibility with polyamides, olefinic elastomers are widely used with grafted maleic anhydride. The maleic anhydride functional group can react with the amine and amide groups of polyamides, resulting in a finer dispersion of elastomers [7].

The cavitation of elastomer particles associated to matrix shear yielding are the main toughening mechanism for polyamide/ elastomer blends [8]. The toughness of materials is related to their deformation behavior and fracture mechanisms. Nevertheless, rubber toughening of polyamides is often achieved at the expense of their stiffness. So, in order to obtain materials with balanced

\footnotetext{
* Corresponding author.

E-mail address: aurelie.taguet@mines-ales.fr (A. Taguet).
} 
properties, ternary nanocomposites have attracted a great deal of interest, especially using organoclays [9-14]. However, the influence of organoclays on the phase diagram of immiscible polymer blends remains unclear. Several explanations have been proposed such as: a compatibilization effect by the clay organomodifier present in excess [15], a viscosity increase of the polymer matrix [16], an emulsification effect of organoclay [17] or a preventing effect of exfoliated platelets on the coalescence phenomenon of the dispersed domains [18]. However, the incorporation of organoclays can also hinder the compatibilization ability of the maleic modification since some authors [13,19] have noticed that particles size increase upon organoclay addition. Consequently, toughening becomes difficult and only achievable through the addition of large rubber contents, entailing a decrease of stiffness [20].

Halloysite nanotubes (HNTs) are a mineral close to kaolin, with the chemical composition $\mathrm{Al}_{2} \mathrm{Si}_{2} \mathrm{O}_{5}(\mathrm{OH})_{4} \cdot \mathrm{nH}_{2} \mathrm{O}$. HNTs silicate sheets presents a coiled structure with a lumen. This clay has many advantages such as biocompatibility, good thermal stability and reinforcing effect [21], leading to a wide range of applications. Various polyamide/halloysite nanocomposites systems were reported in literature and increase of Young's modulus and tensile strength are mentioned, as well as higher thermal stability, nucleating effect and fire retardancy [22-25]. There are a few reported works on the use of halloysite in polyamide-toughened blends. Sharif et al. [26] obtained a superior PA6/epoxidized natural rubber (ENR)/HNTs ternary nanocomposite with 4 wt $\%$ of HNTs and 15 wt\% of ENR thanks to the preferable interfacial interaction between the three components provided by the epoxide group of ENR. In our previous works, halloysite was successfully modified by styrene/(methacryloyloxy)methyl phosphonic acid (P(S-co-MAPC1(OH) 2$)$ ) copolymer on its inner surface [27]. This modified halloysite was then used as a compatibilizing agent in various PS/PA11 blends.

The main objective of this paper is to understand the properties and morphologies of PA11/SEBS-g-MA blends brought by the functionalized halloysite with SEBS chains. To this aim, halloysite was modified in our laboratory via a two steps procedure and then incorporated by melt compounding at $5 \mathrm{wt} \%$ in a PA11/SEBS-g-MA blend (85/15 w/w). Moreover, the results were compared to those of a pristine PA11 and a PA11 reinforced with bare halloysite.

\section{Experimental}

\subsection{Materials}

Polyamide-11 (Rilsan ${ }^{\circledR}$ LMNO) was kindly supplied by Arkema. This grade is free of any stabilizers or additives. Its mean molecular weight $\mathrm{Mn}=22,000 \mathrm{~g} / \mathrm{mol}$ and average molar weight $=51,000 \mathrm{~g} / \mathrm{mol}$ with a density of $1.02 \mathrm{~g} / \mathrm{cm}^{3}$. SEBS grafted with 1.4-2 wt\% of maleic anhydride (SEBS-g-MA Kraton FG1901G) was purchased from Exxon Mobil Chemical. The ratio of styrene to ethylene/butylene in the triblock copolymer was $30 / 70(\mathrm{w} / \mathrm{w})$ and the melt flow index (MFI at $230{ }^{\circ} \mathrm{C}, 5 \mathrm{Kg}$ load) was $22 \mathrm{~g} / 10 \mathrm{~min}$. Raw halloysite (referenced as Hal) derived from Djebel Debbagh deposit (Guelma, eastern region of Algeria). Halloysite particles having an average diameter of $25 \mu \mathrm{m}$ and a surface area of $51.4 \mathrm{~m}^{2} / \mathrm{g}$ [28]. This halloysite was characterized in details previously [28]. 3-aminopropyltriethoxysilane (APTES) (99\%), ethanol (99\%) and toluene (99.8\%) were purchased from Sigma Aldrich, acetone (99.5\%) from Panreac. Before using, HNTs and polymer pellets were dried under vacuum at $80{ }^{\circ} \mathrm{C}$ for $24 \mathrm{~h}$ and overnight, respectively, to remove moisture traces.

\subsection{Halloysite functionalization}

The halloysite functionalization was performed via a two steps procedure. The first step consisted of a reaction between halloysite and 3-aminopropyltriethoxysilane (APTES). $10 \mathrm{~g}$ of halloysite, $1 \mathrm{~g}$ of APTES and $100 \mathrm{ml}$ of an ethanol/water (90/10 w/w) solution were introduced into a $250 \mathrm{~mL}$ flask fitted with a condenser. The mixture was then stirred and heated at solvent reflux for $15 \mathrm{~h}$. The mixture was next centrifuged (speed: $5000 \mathrm{rpm}$ ) to eliminate the liquid phase and washed three times with acetone. Finally, the obtained halloysite (referenced as Hal-A) was dried under vacuum. The second step consisted of introducing $5 \mathrm{~g}$ of Hal-A with $0.5 \mathrm{~g}$ of SEBS-g-MA into a flask fitted with a condenser containing $100 \mathrm{ml}$ of toluene. The mixture was then stirred and heated at solvent reflux for $15 \mathrm{~h}$. The mixture was further centrifuged (speed: $5000 \mathrm{rpm}$ ) to eliminate the liquid phase and washed twice with toluene and once with acetone. Finally, the clay was dried under vacuum before characterization and referenced as Hal-S.

\subsection{Samples preparation}

Bare and modified halloysite were incorporated at $5 \mathrm{wt} \%$ in various ternary blends compositions with a constant PA11/SEBS-gMA ratio (85/15 w/w). For comparison, neat PA11 and PA11/halloysite nanocomposite (5 wt $\%$ ) were also prepared and Table 1

Table 1

Code and composition of the studied materials.

\begin{tabular}{llll}
\hline Material & PA11/SEBS-g-MA & Hal (wt $\%)$ \\
\hline PA11 & $100 / 0$ & 0 & 0 \\
PA/H & $100 / 0$ & 5 & 0 \\
PA/mSEBS & $85 / 15$ & 0 & 0 \\
PA/mSEBS/H & $85 / 15$ & 5 & 0 \\
PA/mSEBS/HS & $85 / 15$ & 0 & 5 \\
\hline
\end{tabular}


summarizes the studied compositions. The samples were prepared by melt mixing under vacuum in a semi-industrial twin screw extruder (BC 21 Clextral) at a screw speed of $250 \mathrm{rpm}$ with a screw diameter (D) of $25 \mathrm{~mm}$ and length to diameter ratio (L/D) of 48 . The temperature profile was $140 / 250 / 245 / 235 / 230{ }^{\circ} \mathrm{C}$ from hopper to die. After pelletizing, the nanocomposites granules were dried under vacuum at $80^{\circ} \mathrm{C}$ overnight and then injection molded into standard test specimens for tensile, impact and dynamic mechanical analyses using an injection molding machine KM50-180X (Krauss Maffei). The temperature profile setting ranged from 220 to $225^{\circ} \mathrm{C}$ and the mold temperature was kept at $40{ }^{\circ} \mathrm{C}$. Holding pressure and screw rotation speed were 135 bar and $100 \mathrm{rpm}$, respectively, with a throughput of $50 \mathrm{~cm}^{3} / \mathrm{s}$.

\subsection{Characterization}

\subsubsection{Fourier transform infrared spectroscopy}

The surface modification of halloysite after grafting was investigated by Fourier transform infrared (FTIR) spectroscopy. FTIR was performed on a spectrometer IFS 66 (Bruker) on $\mathrm{KBr}$ pellets (1:99 ratio) and spectra were obtained by collecting 64 scans between 400 and $4000 \mathrm{~cm}^{-1}$ with a resolution of $2 \mathrm{~cm}^{-1}$.

\subsubsection{Py-GC/MS}

A Pyroprobe 5000 pyrolyzer (CDS analytical) was used to flash pyrolyze the samples in a helium environment. This pyrolyzer is supplied with an electrically heated platinum filament. One coil probe enables the pyrolysis of samples ( $<1 \mathrm{mg})$ placed in a quartz tube between two pieces of rockwool. The sample was heated at $900{ }^{\circ} \mathrm{C}$. The temperature was held for $15 \mathrm{~s}$, and then the gases were drawn to the gas chromatograph for $5 \mathrm{~min}$. The pyroprobe 5000 is interfaced to a 450 -GC chromatograph (Varian) by means of a chamber heated at $270{ }^{\circ} \mathrm{C}$. In the oven, the initial temperature of $70{ }^{\circ} \mathrm{C}$ was raised to $250{ }^{\circ} \mathrm{C}$ at $10{ }^{\circ} \mathrm{C} / \mathrm{min}$. The column is a Varian Vf$5 \mathrm{~ms}$ capillary column $(30 \mathrm{~m} \times 0.25 \mathrm{~mm}$; thickness $=0.25 \mu \mathrm{m})$ and helium $(1 \mathrm{~L} / \mathrm{min})$ was used as carrier gas, a split ratio was set to 1:50. The gases were introduced from the GC transfer line to the ion trap analyzer of the 240-MS mass spectrometer (Varian) through the direct-coupled capillary column.

\subsubsection{Thermogravimetric analysis}

The mass loss of the halloysites and the blends formulations was studied by thermal gravimetric analysis (TGA). The analyses were performed by a thermogravimetric analyzer Setsys Evolution (Setaram). In order to remove the physisorbed water of the halloysites, an isothermal step $\left(10 \mathrm{~min}, 110^{\circ} \mathrm{C}\right)$ was performed before starting the analysis and then the samples were heated to $900{ }^{\circ} \mathrm{C}$ at a heating rate of $10{ }^{\circ} \mathrm{C} / \mathrm{min}$. While the blends samples were heated to $600{ }^{\circ} \mathrm{C}$ at $10{ }^{\circ} \mathrm{C} / \mathrm{min}$. Measurements were carried out under nitrogen atmosphere with a flow rate of $20 \mathrm{ml} / \mathrm{min}$ on samples of approximately $20 \mathrm{mg}$.

\subsubsection{Scanning electron microscopy}

Scanning electron microscopy was used to observe HNTs and SEBS-g-MA nodules state of dispersion in the matrix. An environmental SEM Quanta 200 FEG (FEI Company) was operated under high vacuum at $10 \mathrm{kV}$. The cryo-fractured surface samples were etched in toluene for $72 \mathrm{~h}$ for the extraction of the rubber phase and then coated with a thin carbon layer. SEM was also used to examine the fracture surface of the samples after Charpy impact test.

\subsubsection{Transmission electron microscopy}

Nanocomposites morphology was examined closer by TEM. Micrographs were obtained with a JEOL 1200EX TEM (JEOL) operating at an accelerating voltage of $100 \mathrm{kV}$. The TEM samples were embedded in a LR white resin and ultrathin-sectioned at $70 \mathrm{~nm}$ using a Leica EM UC7 ultra-microtome with a diatome diamond knife Ultra 45 (Nissei Sangyo). Sections were collected on 300 mesh copper grids coated with carbon film.

\subsubsection{Atomic force microscopy}

An AFM MFP-3D Infinity (Asylum Research) was used in the tapping mode at a resonant frequency of approximately $285 \mathrm{kHz}$ with spring constants of $32 \mathrm{~N} / \mathrm{m}$. Specimens were fixed on a metallic support using silver glue or graphite tape.

\subsubsection{Differential scanning calorimetry}

The melting and crystallization behaviors of samples were investigated by differential scanning calorimetry (DSC) with a Pyris Diamond DSC (Perkin Elmer Instruments) under nitrogen environment $(20 \mathrm{ml} / \mathrm{min})$. Specimens of about $10 \mathrm{mg}$ were heated from 30 to $220{ }^{\circ} \mathrm{C}$ at a rate of $10{ }^{\circ} \mathrm{C} / \mathrm{min}$ (first heating scan), equilibrated at $220{ }^{\circ} \mathrm{C}$ for $5 \mathrm{~min}$ then cooled at $10^{\circ} \mathrm{C} / \mathrm{min}$ to $30{ }^{\circ} \mathrm{C}$, equilibrated again at $30^{\circ} \mathrm{C}$, afterwards heated again (second heating scan) at $10^{\circ} \mathrm{C} / \mathrm{min}$. The measurements were performed from cooling and second heating scans, whereas, the first heating scan was made to eliminate the samples thermal history. Crystallization temperature $\left(\mathrm{T}_{\mathrm{c}}\right)$, melting temperature $\left(\mathrm{T}_{\mathrm{m}}\right)$ and melting enthalpy $\left(\Delta \mathrm{H}_{\mathrm{m}}\right)$ of the PA11 phase were determined. The degree of crystallinity $\left(\mathrm{X}_{\mathrm{c}}\right)$ was calculated using Eq. (1):

$$
\mathrm{X}_{\mathrm{c}}=\Delta \mathrm{H}_{\mathrm{m}} /\left(\Delta \mathrm{H}_{\mathrm{m}}^{\circ}\left(1-\mathrm{w}_{\mathrm{t}}\right)\right)
$$

where $\Delta \mathrm{H}_{\mathrm{m}}$ is the melting enthalpy, $\Delta \mathrm{H}_{\mathrm{m}}^{\circ}$ the melting enthalpy of the $100 \%$ crystalline polymer $\left(\Delta \mathrm{H}_{\mathrm{m}}^{\circ}=206 \mathrm{~J} / \mathrm{g}[29]\right)$ and $\mathrm{w}_{\mathrm{t}}$, the PA11 weight fraction in the nanocomposite.

At least two analyses were carried out for each formulation. 


\subsubsection{Mechanical properties}

Stress-strain analysis was evaluated from ISO IA type tensile bars according to ISO 527 standard test procedure. Young's modulus was accurately measured using an extensometer clip-on incremental (Zwick Roell) at a cross-head speed of $1 \mathrm{~mm} / \mathrm{min}$, whereas yield strength and elongation at break were determined at a speed of $20 \mathrm{~mm} / \mathrm{min}$. The measurements were carried out with a tensile machine Zwick Z010 (Zwick Roell) at environmental conditions. Prior to testing, the samples were stored at $23{ }^{\circ} \mathrm{C}$ and $50 \% \mathrm{RH}$ for 10 days, according to ISO 527 standard.

Notched Charpy impact strength of the samples was determined using a Zwick 5102 pendulum impact tester (Zwick Roell) according to ISO 179 standard test procedure, on notched specimens of $80 \times 10 \times 4 \mathrm{~mm}^{3}$ and a depth notch of $2.0 \mathrm{~mm}$. Prior to testing, all specimens were stored as dry as molded at $23{ }^{\circ} \mathrm{C}$ and $0 \% \mathrm{RH}$ for 10 days.

For mechanical properties, at least ten specimens of each formulation were tested.

\subsubsection{Viscoelastic behavior}

The viscoelastic behavior of PA11/SEBS-g-MA blends was studied by dynamic mechanical analysis (DMA). The analysis was performed under dual cantilever mode using a dynamic mechanical analyzer DMA $50 \mathrm{~N}$ (Metravib) on samples of $55 \times 10 \times 4 \mathrm{~mm}^{3}$ cut from ISO 527 1A tensile test bars. Dynamic strain sweep was first performed to determine the linear viscoelastic range of the materials and then tests were accomplished under nitrogen atmosphere at constant amplitude of $5 \mu \mathrm{m}$ and frequency of $5 \mathrm{~Hz}$ at a heating rate of $3{ }^{\circ} \mathrm{C} / \mathrm{min}$ in the temperature range from -100 to $120{ }^{\circ} \mathrm{C}$. Three experiments were conducted for each composition.

\section{Results and discussion}

\subsection{Characterization of the functionalization}

To improve the mechanical performances of PA11/SEBS-g-MA/halloysite ternary nanocomposites, a new strategy for halloysite functionalization was developed. This strategy based on a two-step procedure is illustrated in Fig. 1.

The first step is the halloysite treatment by APTES to introduce amine groups at the filler surface. This silylation reaction is not carried out in anhydrous condition and the auto-condensation of the silanes units leads to the formation of a multilayer grafting. The second step is the functionalization of halloysite nanotubes with SEBS chains by a reaction between the amine groups and maleic anhydride groups of the SEBS-g-MA. This reaction leads to the formation of an amide group and subsequently, to a covalent bond between halloysite external surface and SEBS chains. In order to verify the different grafting steps, Hal, Hal-A and Hal-S samples have been characterized by FTIR spectroscopy, TGA and Py-GC/MS techniques.

Fig. 2 shows FTIR spectra of Hal, Hal-A and Hal-S. After the first step of functionalization, a weak band can be observed at $2930 \mathrm{~cm}^{-1}$ for Hal-A (Fig. 2b). It is characteristic of C-H stretching due to the alkyl group introduced by APTES treatment. Also we note a decrease in the intensity of the $\mathrm{O}-\mathrm{H}$ stretching bands at 3620 and $3695 \mathrm{~cm}^{-1}$ which is the sign of halloysite modification with APTES [30]. After the second step, Hal-S exhibits peaks at 2855 and $2926 \mathrm{~cm}^{-1}$ assigned to the symmetric and asymmetric C-H stretching, respectively, characteristic of the SEBS chains grafted at the halloysite surface. A more intense decrease of the intensity of

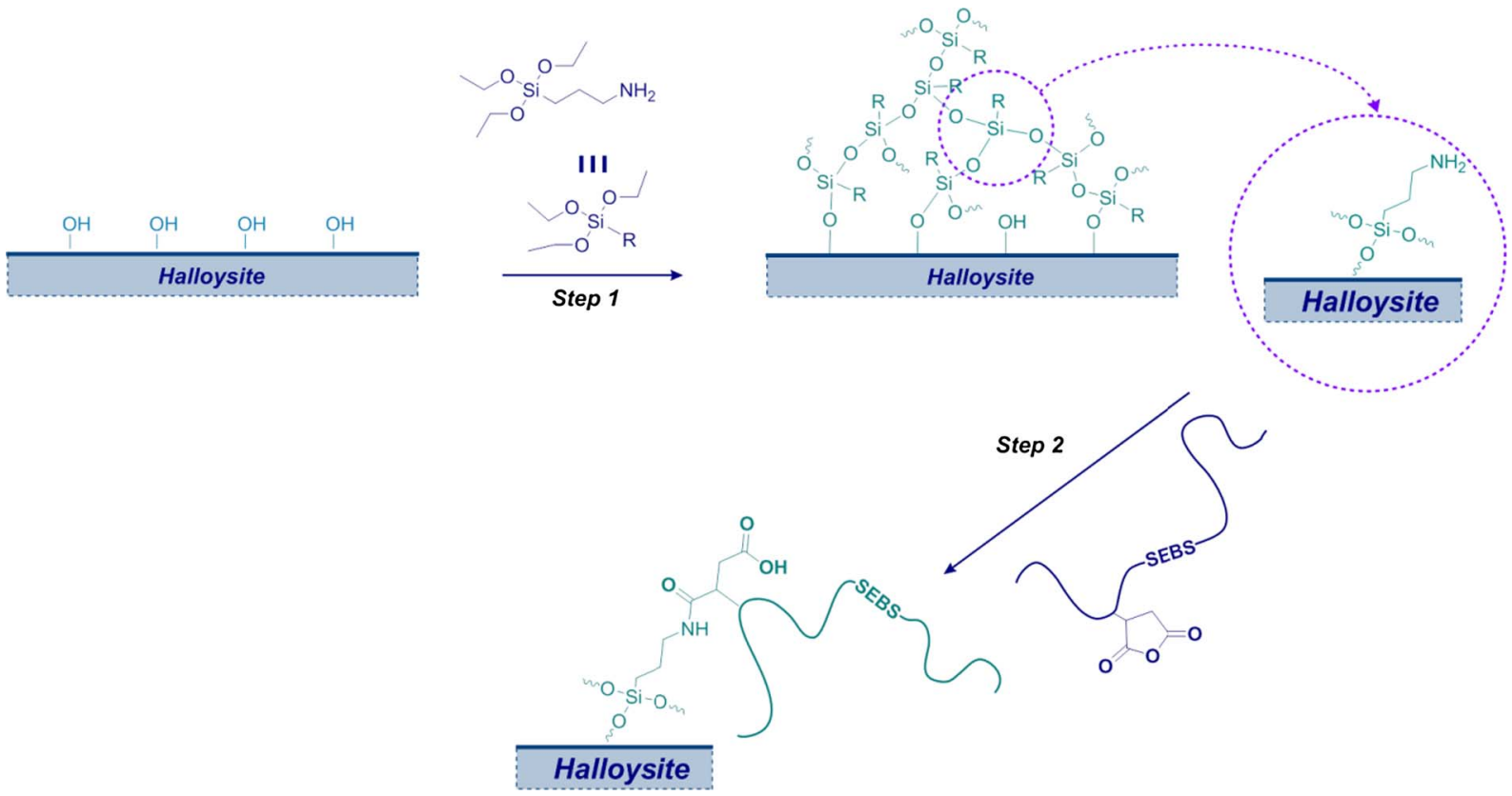

Fig. 1. Scheme of halloysite functionalization with SEBS via a 2 steps procedure. Steps 1 and 2 lead to Hal-A and Hal-S, respectively. 

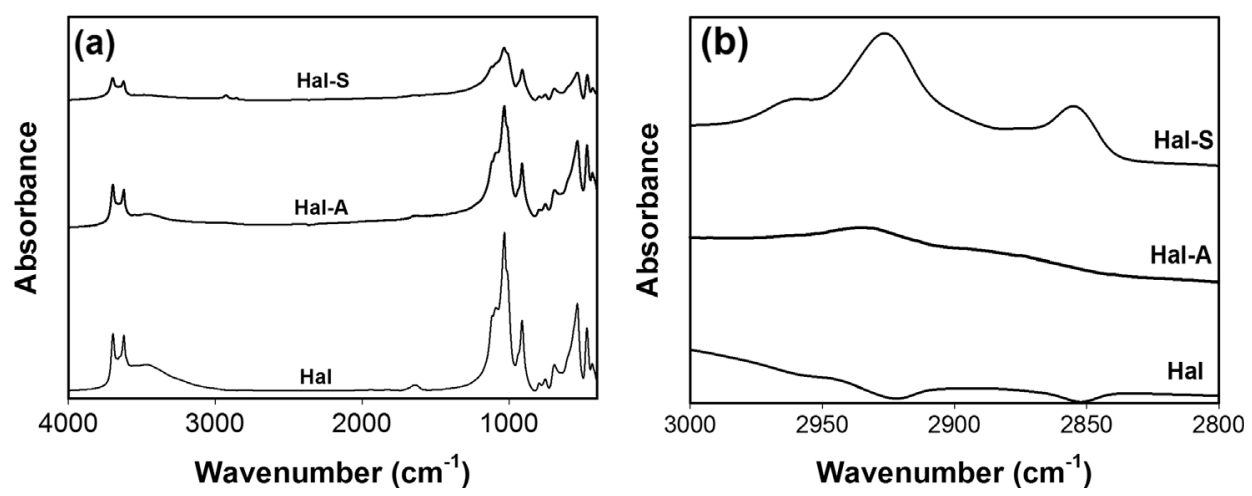

Fig. 2. FTIR spectra of Hal, Hal-A and Hal-S (a). The methylene stretching region (b).

the $\mathrm{O}-\mathrm{H}$ stretching band at $3620 \mathrm{~cm}^{-1}$ and $3695 \mathrm{~cm}^{-1}$ is also visible. These observations indicate the successful reaction between the maleic anhydride groups of SEBS-g-MA and the $\mathrm{NH}_{2}$ functions of Hal-A surface, leading to a halloysite grafted with SEBS chains.

TGA and differential thermogravimetric (DTG) curves of the clay samples are displayed in Fig. 3. As evidenced, all halloysites show a first stage of thermal decomposition up to $240{ }^{\circ} \mathrm{C}$ due to the release of the remaining adsorbed water (surface and interlayer) [31]. Regarding the DTG curves (Fig. 3b), the pristine clay exhibits a second and main mass loss step of about $11.5 \%$ between 400 and $590{ }^{\circ} \mathrm{C}$ corresponding to the structural dehydroxylation of the hydroxyl groups [31]. However, Hal-A and especially Hal-S, features a more pronounced loss, which was attributed to the decomposition of the grafted organic part. Indeed, Hal-A features the same loss but at higher temperatures $\left(410-630^{\circ} \mathrm{C}\right)$. This shift towards higher temperature values is ascribed to the disappearance of the hydroxyl groups of halloysite surface that have been bonded with APTES. Finally, Hal-S exhibits two main steps of mass loss. The first one of $7.5 \mathrm{wt} \%$ in the temperature range $330-440{ }^{\circ} \mathrm{C}$, corresponds to the decomposition of SEBS-g-MA [32]. The second one of $9 \mathrm{wt} \%$ between 440 and $590{ }^{\circ} \mathrm{C}$, at a lower temperature compared to raw halloysite, can be attributed to the dehydroxylation of the hydroxyl groups. TGA was used to quantify the grafting rate. For the pristine halloysite, the residue at $900{ }^{\circ} \mathrm{C}$ is $84.1 \mathrm{wt} \%$, while it is $81.5 \mathrm{wt} \%$ and $79.1 \mathrm{wt} \%$ for Hal-A and Hal-S, respectively. These additional mass losses of 2.5 and $5 \mathrm{wt} \%$ are related to the efficient grafting of APTES and SEBS-g-MA during each step. Knowing that both APTES and SEBS-g-MA were added at 10 wt $\%$ during the two steps of the functionalization, we can estimate the grafting efficiency of each step to approximately $25 \%$.

Py-GC/MS was also used to evidence the two steps of the functionalization and the obtained results are presented in Fig. 4. The first observation after halloysite modification is the disappearance of the main observed peak in Hal that is assigned to sulphur fraction. This disappearance is due to a purification of the clay through the grafting process [27]. After the first step, the chromatogram shows the appearance of several peaks corresponding to the formation of aromatic molecules (benzene, toluene...) which can be attributed to the decomposition of the grafted APTES. The second step leads to the appearance of a new intense peak corresponding to styrene. The formation of styrene is ascribed to the decomposition of the styrenic blocks of the grafted SEBS chains.

\subsection{Morphology}

The morphology of the blends was studied at different scales. SEM images allowed investigating the state of dispersion of both SEBS-g-MA phase and clay in the blend. SEM micrographs of cryofractured surfaces of neat and filled PA11/SEBS-g-MA blends are presented in Fig. 5. The images reveal a homogeneous and uniform dispersion for bare and modified halloysite particles in the matrix, most of them being dispersed at the nanometer scale. However, a few micronic particles resulting from the comminution process of raw halloysite are also visible as aggregates but they are less than $10 \mu \mathrm{m}$ in size. The fine dispersion of halloysite particles in PA11 may be the result of a good affinity between the HNTs and the PA11 matrix. No significant differences can be observed using SEM
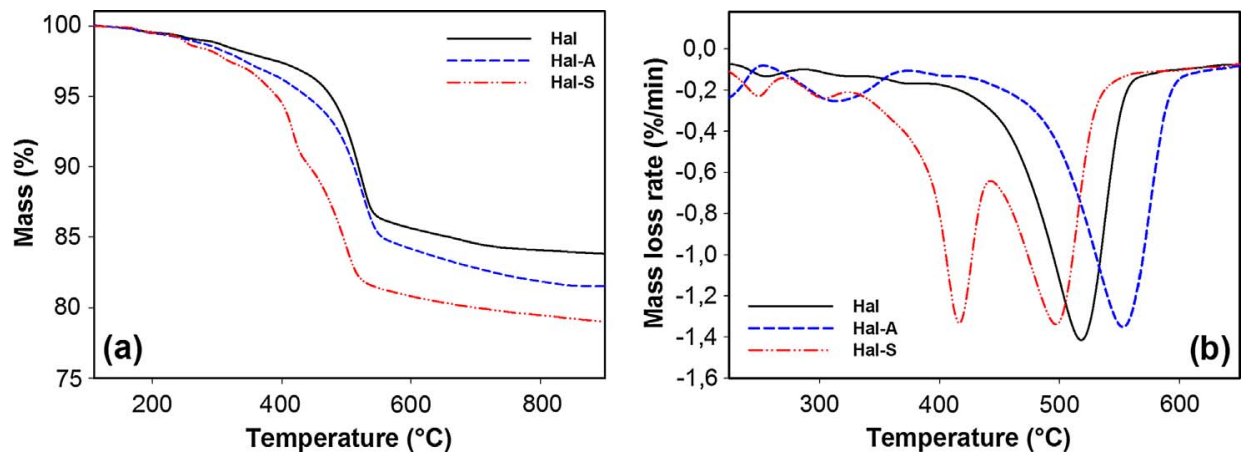

Fig. 3. TGA (a) and DTG (b) curves of Hal, Hal-A and Hal-S. 


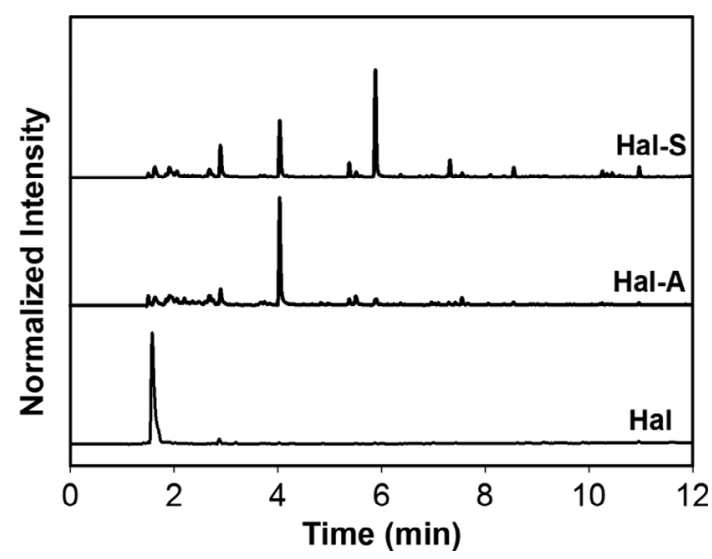

Fig. 4. Py-GC/MS chromatograms of Hal, Hal-A and Hal-S.

between Hal and Hal-S despite its functionalization. From Fig. 5c-e, a uniform dispersion of the holes corresponding to the extracted SEBS-g-MA nodules can be further observed, most of them being at a submicron scale. However, nodules size increases after bare halloysite incorporation while they remain at the same scale when modified halloysite was used. The reduced SEBS-g-MA nodules size in the case of PA/mSEBS/HS can be due to a more effective compatibilizing effect through the functionalizing process [12]. However, the presence at submicron and nanometer scale of both SEBS-g-MA nodules and halloysite nanotubes, respectively, requires the use of TEM to investigate the morphology.

Consequently, TEM pictures were also taken and are shown in Fig. 6. SEBS-g-MA nodules correspond to the small white circles, while the dark gray background forms the PA11 matrix (Fig. 6a). We observe from Fig. 6b that the bare halloysite is rather well dispersed with the presence of few small aggregates, as previously shown by SEM images (Fig. 5). Nevertheless, after functionalization, a few larger agglomerates of Hal-S nanotubes and SEBS-g-MA nodules are formed, as evidenced by the white spots on Fig. 6c. These observations can be explained by the stronger interaction between halloysite and SEBS-g-MA after functionalization of halloysite by grafting SEBS chains.

To complete the morphological study, AFM images using tapping mode were also obtained from the different blends compositions (Fig. 7). Initial dispersion of the SEBS-g-MA nodules (in blue) in the PA11 matrix (in yellow) is seen from Fig. 7a. After bare halloysite addition (Fig. 7b), SEBS-g-MA nodules size and shape are affected. Indeed, we observe a more uniform distribution of elongated nodules in the PA11 matrix. Finally, after modified halloysite incorporation (Fig. 7c), the dispersion of SEBS-g-MA nodules is more homogeneous and highly spherical. The specific localization and affinity of modified HNTs into the blend can induce different breaking thread/coalescence process during the sample preparation in twin screw extruder, leading to different SEBS-g-MA dispersed phase shape. The images present also approximate values of modulus for the blend constituents.

\subsection{Thermal properties}

The mass loss of the various nanocomposites samples was investigated by TGA. Thermal gravimetric analysis and differential thermogravimetric (DTG) curves are shown in Fig. 8a and b, respectively. Table 2 summarizes the values of characteristic temperatures at $\mathrm{T}_{5 \%}, \mathrm{~T}_{50 \%}$ and $\mathrm{T}_{\mathrm{mrd}}$ which correspond, respectively, to the initial decomposition temperature at $5 \%$ of degradation, the temperature at $50 \%$ of degradation and the maximum rate of degradation temperature measured at the maximum peak of DTG curve.

Firstly, we observe that PA11 mass loss occurs at higher temperatures when blended with SEBS-g-MA up to $440{ }^{\circ} \mathrm{C}$ due to the chemical interaction between PA11 and maleic anhydride groups of SEBS-g-MA. At further increase in temperature, SEBS-g-MA decomposition induces a faster decomposition of the blend [33]. The incorporation of both bare and functionalized HNTs induce higher temperature of mass loss for PA11/SEBS-g-MA blends, being however much higher for Hal-S. Thus, all the characteristic temperatures of the nanocomposites shift towards higher values $\left(+14{ }^{\circ} \mathrm{C}\right.$ for $\mathrm{T}_{5 \%}$ and $+11{ }^{\circ} \mathrm{C}$ for $\mathrm{T}_{\mathrm{mrd}}$ in the case of PA/mSEBS/HS).

The improved impact of PA/mSEBS/HS could be explained by a better compatibility between PA11 and SEBS-g-MA in the presence of functionalized halloysite. It can be assumed that the presence of halloysite delays the thermal degradation of polymer nanocomposites and this is allowed thanks to its tubular structure with large lumen volume which can allow entrapment of degradation products, resulting in an effective delay in mass transfer of volatile decomposition products [34].

The effects of both halloysites on melting and crystallization behaviors of PA11/SEBS-g-MA blends were studied using DSC. Values of crystallization temperature $\left(\mathrm{T}_{\mathrm{c}}\right)$, melting temperature $\left(\mathrm{T}_{\mathrm{m}}\right)$ and degree of crystallinity $\left(\mathrm{X}_{\mathrm{c}}\right)$ are reported in Table 2 . The analysis of the DSC data indicates that the crystallization behavior of the blends is slightly affected by the presence of halloysite. Indeed, from Table 2, it can be observed that $T_{c}, T_{m}$ and $X_{c}$ of the ternary blends are quite the same. This indicates a restrained nucleating effect of halloysite in the PA11 matrix. The presence of some aggregates in the PA11 matrix, as shown previously by the SEM micrographs (see Fig. 5) can explain this poor nucleating effect, since each aggregate could only act as one nucleus for the crystallization process [23]. Nevertheless, we note an increase of the crystallization temperature $\left(+3.5{ }^{\circ} \mathrm{C}\right)$ and rate $(+5 \%)$ compared 

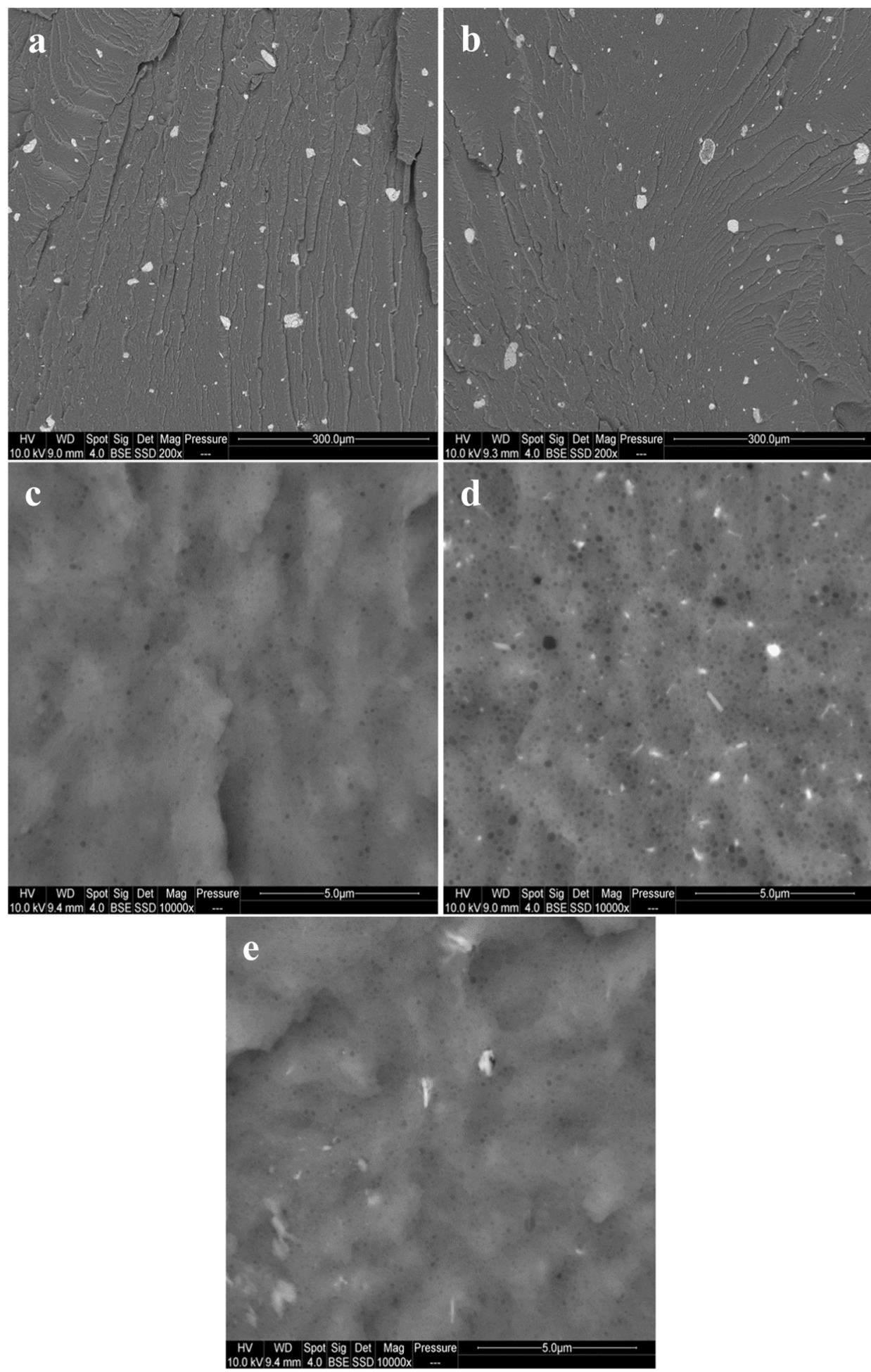

Fig. 5. SEM micrographs under magnification $\mathrm{x} 200$ of $\mathrm{PA} / \mathrm{mSEBS} / \mathrm{H}$ (a) and PA/mSEBS/HS (b). Under magnification $\times 10,000$ of PA/mSEBS (c), PA/mSEBS/H (d) and PA/mSEBS/HS (e).

to neat PA11. This can be due to the higher SEBS-g-MA viscosity than PA11 at the processing temperature, which facilitates nucleation of the polyamide phase [3]. On the other hand, the melting behavior remains unaltered as the melting temperature $\left(\mathrm{T}_{\mathrm{m}}\right)$ stays unchanged whatever the composition. 


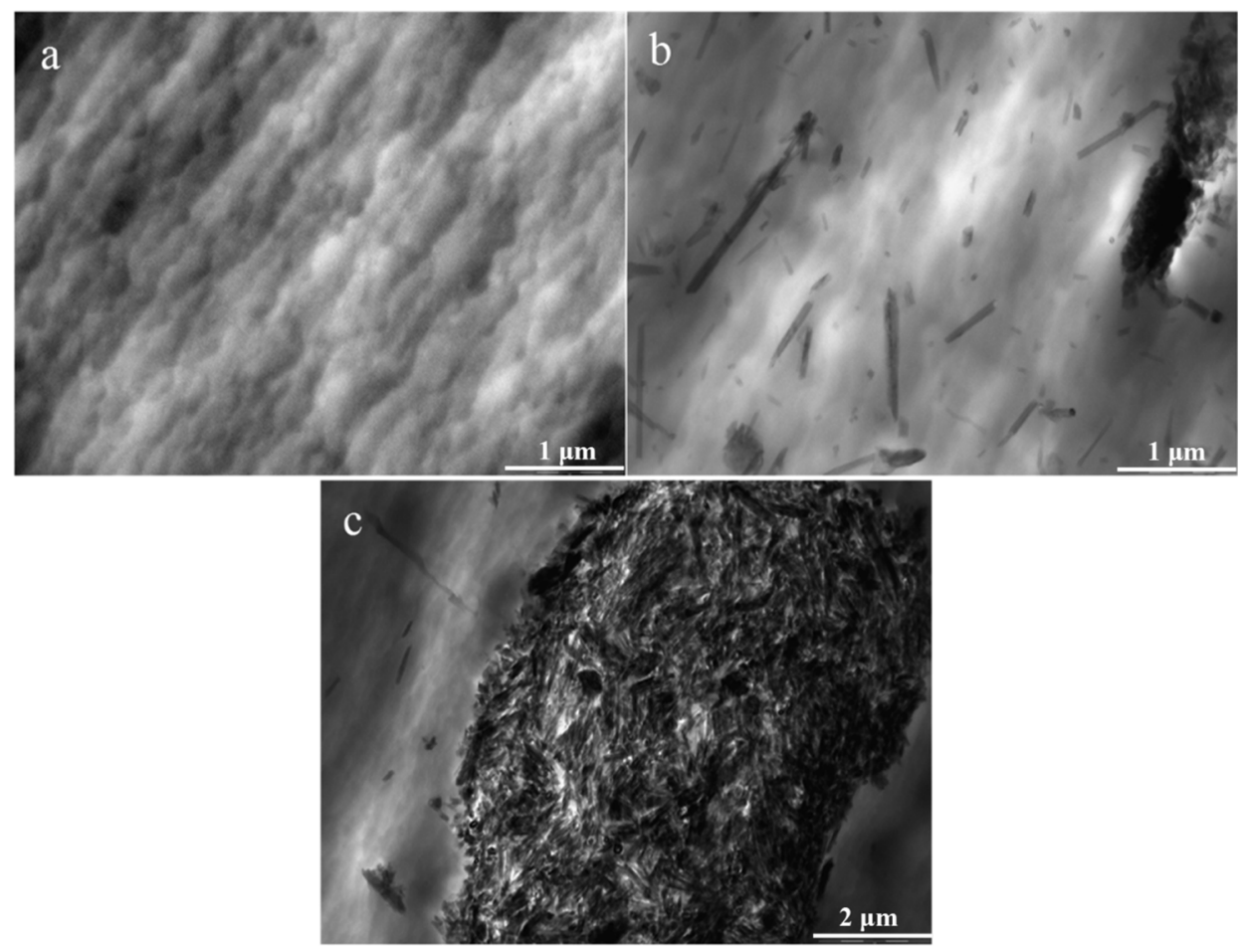

Fig. 6. TEM micrographs of PA/mSEBS (a), PA/mSEBS/H (b) and PA/mSEBS/HS (c).
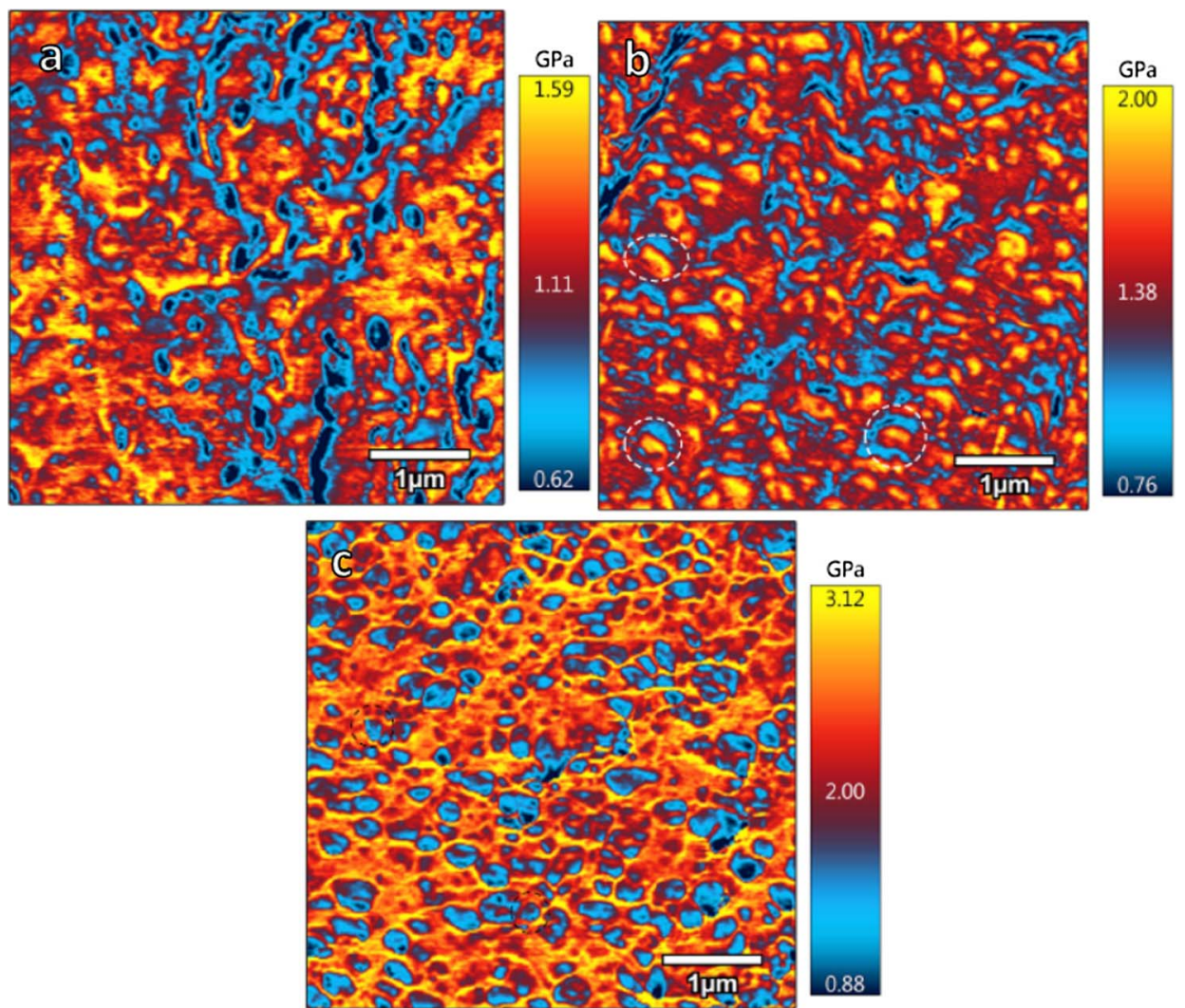

Fig. 7. AFM images of PA/mSEBS (a), PA/mSEBS/H (b) and PA/mSEBS/HS (c). 

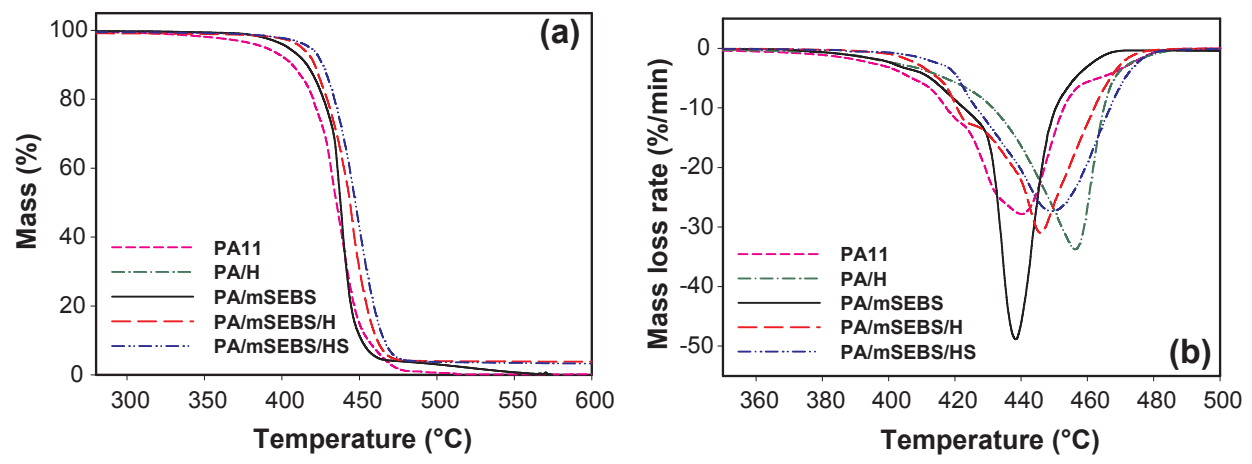

Fig. 8. TGA (a) and DTG (b) curves of the different compositions.

Table 2

Main thermal characteristic temperatures of the samples obtained by TGA and DSC.

\begin{tabular}{llllrr}
\hline Material & $\mathrm{T}_{5 \%}\left({ }^{\circ} \mathrm{C}\right)$ & $\mathrm{T}_{50 \%}\left({ }^{\circ} \mathrm{C}\right)$ & $\mathrm{T}_{\mathrm{mrd}}\left({ }^{\circ} \mathrm{C}\right)$ & $\mathrm{T}_{\mathrm{m}}\left({ }^{\circ} \mathrm{C}\right)$ & $\mathrm{X}_{\mathrm{c}}(\%)$ \\
\hline PA11 & $388.4 \pm 1.4$ & $434.6 \pm 1.3$ & $439.1 \pm 1.7$ & $191.2 \pm 1.6$ \\
PA/H & $397.6 \pm 1.2$ & $448.5 \pm 1.4$ & $456.8 \pm 1.5$ & $190.8 \pm 1.5$ & $164.1 \pm 0.9$ \\
PA/mSEBS & $404 \pm 1.1$ & $437.7 \pm 1.5$ & $438.1 \pm 1.5$ & $191.9 \pm 0.3$ & $167.6 \pm 0.9$ \\
PA/mSEBS/H & $412.8 \pm 1.3$ & $443.9 \pm 0.7$ & $446 \pm 0.1$ & $191.3 \pm 0.6$ \\
PA/mSEBS/HS & $418 \pm 0.9$ & $447.4 \pm 1$ & $449.4 \pm 0.8$ & $19.3 \pm 0.5$ \\
\hline
\end{tabular}

Table 3

Main mechanical properties of the samples obtained by tensile (Young's modulus, yield stress, strain energy and elongation at break) and impact tests (impact strength).

\begin{tabular}{lllll}
\hline Material & Young's Modulus $(\mathrm{MPa})$ & Yield stress $(\mathrm{MPa})$ & Strain energy $(\mathrm{J})$ & Elongation at break $(\%)$ \\
\hline PA11 & $1220 \pm 55$ & $41.2 \pm 0.6$ & $234.6 \pm 9.2$ & $228 \pm 14$ \\
PA/H & $1511 \pm 75$ & $44.6 \pm 0.3$ & $94.1 \pm 9.7$ & $94 \pm 16$ \\
PA/mSEBS & $1123 \pm 31$ & $37.5 \pm 0.6$ & $255.8 \pm 10.6$ & $226 \pm 24$ \\
PA/mSEBS/H & $1121 \pm 12$ & $36.6 \pm 0.2$ & $207.7 \pm 7.7$ & $203 \pm 2$ \\
PA/mSEBS/HS & $986 \pm 20$ & $31.8 \pm 0.2$ & $298.4 \pm 11.3$ & $277 \pm 32$ \\
\end{tabular}

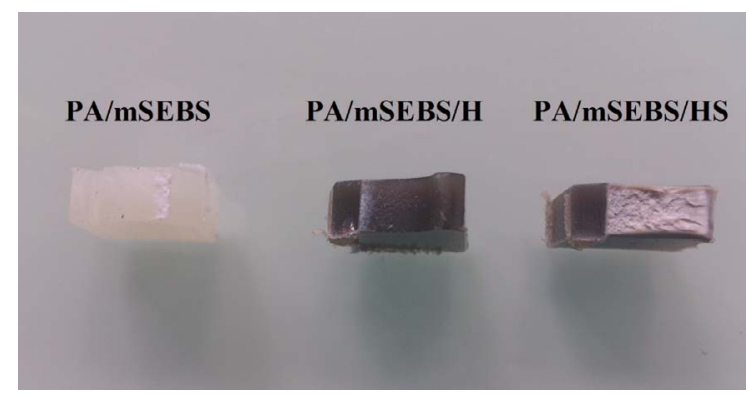

Fig. 9. Pictures of fracture surface after Charpy test of PA/mSEBS, PA/mSEBS/H and PA/mSEBS/HS.

\subsection{Mechanical properties}

Both tensile test and impact strength values of neat and filled blends are listed in Table 3. The data indicate that blending PA11 with SEBS-g-MA $(85 / 15 \mathrm{w} / \mathrm{w})$ results in a rise of strain energy, measured as the area under stress-strain curves ( $+9 \%)$ and impact strength $(+200 \%)$, while Young's modulus and elongation at break remain almost constant. Indeed, regarding toughness and impact properties, in addition to rubber tearing or bridging as toughening mechanisms, SEBS-g-MA nodules provide cavitation which relieves the triaxial stress state in front of the crack tip and allows the matrix deforming considerably before fracture through shear yielding [20]. SEBS-g-MA can also delay crack propagation during testing, thereby dissipating more energy. The presence of 5 wt $\%$ of halloysite in PA11 leads to higher Young's modulus $(+25 \%)$ and a drop of elongation at break and toughness $(-60 \%$ for strain energy and $-44 \%$ for impact strength) compared to neat PA11. The results are consistent with the literature data [12,22,35-38]. In the case of halloysite, no intercalation or exfoliation can be found, so the enhancement of strength is only due to the intrinsic stiffness of the individually dispersed halloysite nanotubes and their interactions through hydrogen bonds with polyamide [37]. Regarding the 

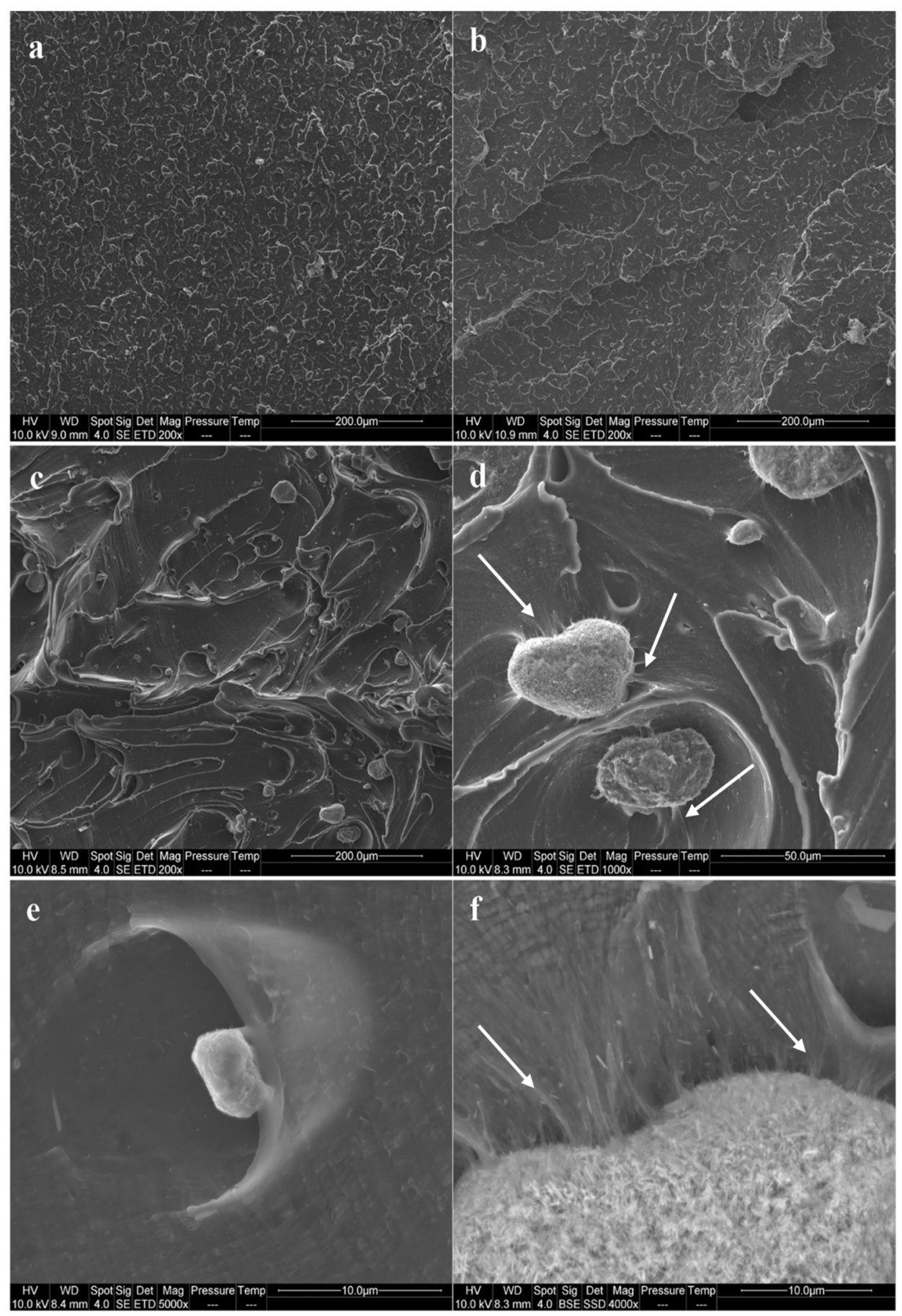

Fig. 10. SEM micrographs of the fractured zone of the samples after impact test: PA/mSEBS (a), PA/mSEBS/H (b) and PA/mSEBS/HS (c-f).

impact of halloysite on the mechanical properties of PA11/SEBS-g-MA blends, a decrease of strain energy and elongation at break is noticed in the presence of bare halloysite. Thus, PA/mSEBS/H exhibits a $-18.9 \%$ decrease in strain energy, a $-10 \%$ decrease in elongation at break and a $-320 \%$ decrease in impact strength with the same value of Young's modulus. However, PA/mSEBS/HS exhibits improved properties (except for Young's modulus) compared to all the compositions. Young's modulus decreases from 12\% but strain energy is increased of $16.8 \%$, elongation at break of $22.5 \%$ and impact strength of $156 \%$, in comparison with unfilled PA11/SEBS-g-MA blend. This enhancement of impact strength is outstanding when compared to neat PA11 and PA/H $(+677$ and $1000 \%$, respectively). Basically, halloysite can play a double role concerning toughness. On one hand, it can enhance the toughness of PA11 nanocomposites by crack-bridging, crack deflection and plastic deformation of the matrix [36,37,39,40], and on the other 


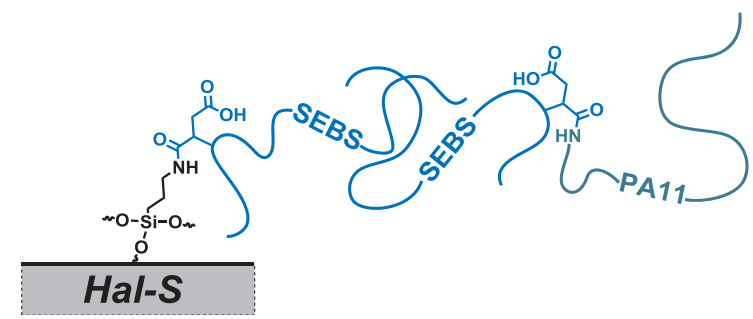

Fig. 11. Schematic representation of the entanglements between the grafted SEBS of Hal-S and the SEBS-g-MA chains of the PA11/SEBS-g-MA blend.
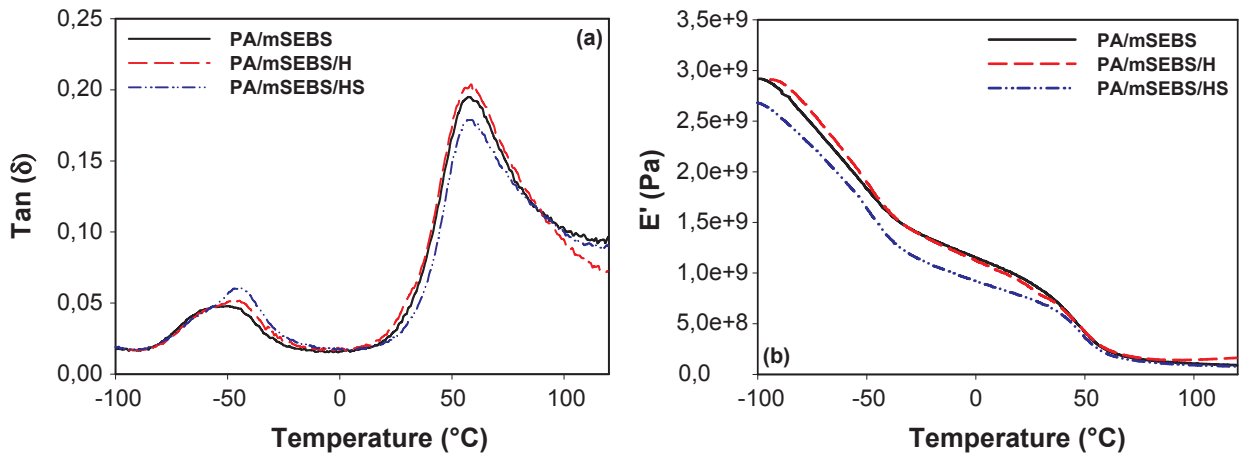

Fig. 12. Variation according to temperature of loss factor (a) and storage modulus (b) of the blends compositions.

hand, halloysite aggregates can cause stress concentrations in the sample, increasing its brittleness. Prashantha et al. [36] ascribe the increase of toughness mainly to the work consumed in the inner fracture process zone to create a new surface (essential work of fracture, $w_{e}$ ), whereas the plastic deformation in the outer zone (non-essential work of fracture, $w_{p}$ ) varies slightly.

Unlike PA/mSEBS and PA/mSEBS/H samples, PA/mSEBS/HS specimens whitened in the zone surrounding fracture during impact testing (see Fig. 9).

This stress whitening is due to the formation of microvoids and shear yielding in the PA11 matrix. Therefore, to examine the fracture surfaces, SEM images were collected after Charpy impact test. As shown in Fig. 10, PA/mSEBS and PA/mSEBS/H exhibit relative uniform and plane fracture surfaces, indicating a brittle fracture. Whereas, PA/mSEBS/HS shows a ductile fracture type (Fig. 10c). It is well known that maleic anhydride can react with the amine end groups of PA11 [41]. Hence, SEBS-g-MA chains of the blend are covalently bonded to the PA11 matrix. And then, the free SEBS chains of the blend can give rise to entanglements with the SEBS grafted on the Hal-S nanotubes (see Fig. 11). The entanglements lead to strong links between modified halloysite agglomerates and the matrix via the dispersed SEBS-g-MA phase (see white arrows on Fig. 10d and f). Hence, during the impact test, the stress applied to the matrix is transmitted to the SEBS-g-MA elastomeric phase via the halloysite nanotubes leading to microvoids that promote stress whitening.

\subsection{Viscoelastic behavior}

Fig. 12 shows the viscoelastic behavior of the blends compositions through the variation according to temperature of mechanical loss factor $(\tan \delta$ ) (Fig. 12a) and storage modulus in flexion (E') (Fig. 12b). From Fig. 12a, we can see that the blends exhibit two peaks of $\tan \delta$ corresponding to $\alpha$ transition $\left(\mathrm{T}_{\mathrm{g}}\right.$ ) of SEBS-g-MA and PA11, respectively. Two phenomena can be observed concerning tan $\delta$ : first, $\mathrm{T}_{\mathrm{g}}$ of SEBS-g-MA $\left(-52{ }^{\circ} \mathrm{C}\right)$ shifts to a higher temperature upon incorporation of halloysite $\left(+8{ }^{\circ} \mathrm{C}\right)$ with higher values of loss factor, especially in PA/mSEBS/HS. Higher $\mathrm{T}_{\mathrm{g}}$ can be explained by the strong link between SEBS-g-MA and halloysite nanotubes that decreases the SEBS-g-MA chains mobility, and increases the energy dissipation at the interface between the elastomeric phase and the clay nanotubes, especially for the functionalized halloysite. While the higher value of the $\tan \delta$ peak of PA/mSEBS/HS is the result of the decrease of its storage modulus. Furthermore, $\mathrm{T}_{\mathrm{g}}$ of the PA11 phase remains at the same temperature whatever the composition $\left(56{ }^{\circ} \mathrm{C}\right)$. Nevertheless, a decrease in loss factor value of the PA11 phase in PA/mSEBS/HS is observed, but cannot be taken into account because of high standard deviation. It can be seen from Fig. 12b that the PA/mSEBS/H nanocomposite exhibits slightly higher values of $\mathrm{E}^{\prime}$ compared to neat blend in the temperature range between -100 and $-45^{\circ} \mathrm{C}$, i.e. under the SEBS-g-MA $\mathrm{T}_{\mathrm{g}}$. At higher temperature (above $-45^{\circ} \mathrm{C}$ ) PA/mSEBS and PA/mSEBS/H show similar values of $\mathrm{E}^{\prime}$, whereas PA/mSEBS/HS ternary blend exhibits lower values of $\mathrm{E}^{\prime}$ and this for temperatures lower than PA11 phase $\mathrm{T}_{\mathrm{g}}\left(56^{\circ} \mathrm{C}\right)$. This drop of $\mathrm{E}^{\prime}$ can be explained by the more uniform dispersion of the SEBS-g-MA nodules in the blends and the presence of halloysite agglomerates in the presence modified halloysite, as seen with SEM, TEM and AFM images of Figs. 5, 6 and 7, respectively. 


\section{Conclusions}

In this work, halloysite was successfully functionalized by bonding SEBS chains on its surface via a two steps procedure. FTIR, TGA and Py-GC/MS evidenced this grafting. The influence of the halloysite functionalization on morphology and properties of PA11/ SEBS-g-MA blends (85/15 w/w) was examined. SEM micrographs revealed homogenous dispersion of halloysite nanotubes and SEBSg-MA nodules in the matrix. Strong interactions were created between modified halloysite and SEBS-g-MA nodules as evidenced by TEM images. The thermal properties of the blend were enhanced in the presence of modified halloysite due to a better compatibility between PA11 and SEBS-g-MA, with no significant effect on the crystallization behavior, determined by TGA and DSC. Moreover, mechanical tests showed further enhancements in terms of toughness of the PA11/SEBS-g-MA blend containing functionalized halloysite. This improvement can be attributed to the strong link between the functionalized HNTs and the SEBS-g-MA phase that induces stress transfer between the PA11 matrix and the modified halloysite.

\section{Acknowledgments}

The authors are grateful to EGIDE for its financial support through the Tassili program 13MDU891, to Jean-Jacques Flat from Arkema, and Soalka for supplying polyamide-11 and raw Algerian halloysite, respectively. The authors are also thankful to Benjamin Gallard of C2MA for his help during samples elaboration and Rafael Barbattini of Asylum Company for his help to perform AFM measurements.

\section{References}

[1] X. He, J. Yang, L. Zhu, B. Wang, G. Sun, P. Lv, I.Y. Phang, T. Liu, Morphology and melt rheology of nylon 11/clay nanocomposites, J. Appl. Polym. Sci. 102 (2006) 542-549, http://dx.doi.org/10.1002/app.24281.

[2] T. Liu, K.P. Lim, W.C. Tjiu, K.P. Pramoda, Z.K. Chen, Preparation and characterization of nylon 11/organoclay nanocomposites, Polymer 44 (2003) 3529-3535, http://dx.doi.org/10.1016/S0032-3861(03)00252-0.

[3] K. Rinawa, S.N. Maiti, R. Sonnier, J.M. Lopez Cuesta, Influence of microstructure and flexibility of maleated styrene-b-(ethylene-co-butylene)-b-styrene rubber on the mechanical properties of polyamide 12, Polym. Bull. 71 (2014) 1131-1152, http://dx.doi.org/10.1007/s00289-014-1115-4.

[4] A.J. Oshinski, H. Keskkula, D.R. Paul, Rubber toughening of polyamides with functionalized block copolymers: 2. Nylon-6,6, Polymer 33 (1992) 284-293, http://dx.doi.org/10.1016/0032-3861(92)90985-6.

[5] M. Diffalah, P. Demont, C. Lacabanne, Thermally stimulated creep (TSCr) study of polyamide 66 and polyamide 66/EPR blends, Thermochim. Acta 226 (1993) 33-42, http://dx.doi.org/10.1016/0040-6031(93)80204-N.

[6] G. Hu, B. Wang, X. Zhou, Effect of EPDM-MAH compatibilizer on the mechanical properties and morphology of nylon 11/PE blends, Mater. Lett. 58 (2004) 3457-3460, http://dx.doi.org/10.1016/j.matlet.2004.07.002.

[7] R.J.M. Borggreve, R.J. Gaymans, Impact behaviour of nylon-rubber blends: 4. Effect of the coupling agent, maleic anhydride, Polymer (Guildf) 30 (1989) 63-70, http://dx.doi.org/10.1016/0032-3861(89)90384-4.

[8] S.C. Tjong, S. Xu, Y.-W. Mai, Tensile deformation mechanism of polyamide 6,6/SEBS-g-MA blend and its hybrid composites reinforced with short glass fibers, J. Mater. Sci. 38 (2003) 207-215, http://dx.doi.org/10.1002/app.11398.

[9] I. González, J.I. Eguiazábal, J. Nazábal, Compatibilization level effects on the structure and mechanical properties of rubber-modified polyamide-6/clay nanocomposites, J. Polym. Sci. Part B Polym. Phys. 43 (2005) 3611-3620, http://dx.doi.org/10.1002/polb.20663.

[10] A. Dasari, Z.Z. Yu, Y.W. Mai, Effect of blending sequence on microstructure of ternary nanocomposites, Polymer 46 (2005) 5986-5991, http://dx.doi.org/10. 1016/j.polymer.2005.05.145.

[11] F.-C. Chiu, S.-M. Lai, Y.-L. Chen, T.-H. Lee, Investigation on the polyamide 6/organoclay nanocomposites with or without a maleated polyolefin elastomer as a toughener, Polymer 46 (2005) 11600-11609, http://dx.doi.org/10.1016/j.polymer.2005.09.077.

[12] I. González, J.I.I. Eguiazábal, J. Nazábal, Nanocomposites based on a polyamide 6/maleated styrene-butylene-co-ethylene-styrene blend: effects of clay loading on morphology and mechanical properties, Eur. Polym. J. 42 (2006) 2905-2913, http://dx.doi.org/10.1016/j.eurpolymj.2006.07.014.

[13] I. Gonzalez, J. Eguiazabal, J. Nazabal, Rubber-toughened polyamide 6/clay nanocomposites, Compos. Sci. Technol. 66 (2006) 1833-1843, http://dx.doi.org/10. 1016/j.compscitech.2005.10.008.

[14] K. Wang, C. Wang, J. Li, J. Su, Q. Zhang, R. Du, Q. Fu, Effects of clay on phase morphology and mechanical properties in polyamide 6/EPDM-g-MA/organoclay ternary nanocomposites, Polymer 48 (2007) 2144-2154, http://dx.doi.org/10.1016/j.polymer.2007.01.070.

[15] M.Y. Gelfer, H.H. Song, L. Liu, B.S. Hsiao, B. Chu, M. Rafailovich, M. Si, V. Zaitsev, Effects of organoclays on morphology and thermal and rheological properties of polystyrene and poly(methyl methacrylate) blends, J. Polym. Sci. Part B Polym. Phys. 41 (2002) 44-54, http://dx.doi.org/10.1002/polb.10360.

[16] Y. Li, H. Shimizu, Novel morphologies of poly(phenylene oxide) (PPO)/polyamide 6 (PA6) blend nanocomposites, Polymer 45 (2004) 7381-7388, http://dx.doi. org/10.1016/j.polymer.2004.09.018.

[17] D. Voulgaris, Emulsifying effect of dimethyldioctadecylammonium-hectorite in polystyrene/poly(ethyl methacrylate) blends, Polymer 43 (2002) 2213-2218, http://dx.doi.org/10.1016/S0032-3861(02)00039-3.

[18] H.S. Lee, P.D. Fasulo, W.R. Rodgers, D.R. Paul, TPO based nanocomposites. Part 1. Morphology and mechanical properties, Polymer 46 (2005) 11673-11689, http://dx.doi.org/10.1016/j.polymer.2005.09.068.

[19] Y.C. Ahn, D.R. Paul, Rubber toughening of nylon 6 nanocomposites, Polymer 47 (2006) 2830-2838, http://dx.doi.org/10.1016/j.polymer.2006.02.074.

[20] I. González, J.I. Eguiazábal, J. Nazábal, Effects of the processing sequence and critical interparticle distance in PA6-clay/mSEBS nanocomposites, Eur. Polym. J. 44 (2008) 287-299, http://dx.doi.org/10.1016/j.eurpolymj.2007.11.027.

[21] M. Liu, Z. Jia, D. Jia, C. Zhou, Recent advance in research on halloysite nanotubes-polymer nanocomposite, Prog. Polym. Sci. 39 (2014) 1498-1525, http://dx. doi.org/10.1016/j.progpolymsci.2014.04.004.

[22] U.a. Handge, K. Hedicke-Höchstötter, V. Altstädt, Composites of polyamide 6 and silicate nanotubes of the mineral halloysite: influence of molecular weight on thermal, mechanical and rheological properties, Polymer 51 (2010) 2690-2699, http://dx.doi.org/10.1016/j.polymer.2010.04.041.

[23] B. Lecouvet, J.G.G. Gutierrez, M. Sclavons, C. Bailly, Structure-property relationships in polyamide 12/halloysite nanotube nanocomposites, Polym. Degrad. Stab. 96 (2011) 226-235, http://dx.doi.org/10.1016/j.polymdegradstab.2010.11.006.

[24] K. Prashantha, M.-F.F. Lacrampe, P. Krawczak, Highly dispersed polyamide-11/halloysite nanocomposites: thermal, rheological, optical, dielectric, and mechanical properties, J. Appl. Polym. Sci. 130 (2013) 313-321, http://dx.doi.org/10.1002/app.39160.

[25] A. Hao, I. Wong, H. Wu, B. Lisco, B. Ong, A. Sallean, S. Butler, M. Londa, J.H. Koo, Mechanical, thermal, and flame-retardant performance of polyamide 11-halloysite nanotube nanocomposites, J. Mater. Sci. (2014). http://dx.doi.org/10.1007/s10853-014-8575-7.

[26] N.F.A. Sharif, Z. Mohamad, A. Hassan, M.U. Wahit, Novel epoxidized natural rubber toughened polyamide 6/halloysite nanotubes nanocomposites, J. Polym. Res. 19 (2011) 9749, http://dx.doi.org/10.1007/s10965-011-9749-5.

[27] M. Sahnoune, A. Taguet, B. Otazaghine, M. Kaci, J.-M. Lopez-Cuesta, Inner surface modification of halloysite nanotubes and its influence on morphology and 
thermal properties of polystyrene/polyamide-11 blends, Polym. Int. 66 (2016) 300-312, http://dx.doi.org/10.1002/pi.5266.

[28] S. Kennouche, N. Le Moigne, M. Kaci, J.C. Quantin, A.S. Caro-Bretelle, C. Delaite, J.M. Lopez-Cuesta, Morphological characterization and thermal properties of compatibilized poly(3-hydroxybutyrate-co-3-hydroxyvalerate) (PHBV)/poly(butylene succinate) (PBS)/halloysite ternary nanocomposites, Eur. Polym. J. 75 (2016) 142-162, http://dx.doi.org/10.1016/j.eurpolymj.2015.12.009.

[29] G. Mago, D.M. Kalyon, F.T. Fisher, Nanocomposites of polyamide-11 and carbon nanostructures: development of microstructure and ultimate properties following solution processing, J. Polym. Sci. Part B Polym. Phys. 49 (2011) 1311-1321, http://dx.doi.org/10.1002/polb.22311.

[30] A.R. Erdogan, I. Kaygusuz, C. Kaynak, A. Riza Erdogan, I. Kaygusuz, C. Kaynak, Influences of aminosilanization of halloysite nanotubes on the mechanical properties of polyamide-6 nanocomposites, Polym. Compos. 35 (2014) 1350-1361, http://dx.doi.org/10.1002/pc.22787.

[31] K. Belkassa, F. Bessaha, K. Marouf-Khelifa, I. Batonneau-Gener, J. Comparot, A. Khelifa, Physicochemical and adsorptive properties of a heat-treated and acidleached Algerian halloysite, Colloids Surf. A Physicochem. Eng. Asp. 421 (2013) 26-33, http://dx.doi.org/10.1016/j.colsurfa.2012.12.048.

[32] S. Jose, P.S. Thomas, S. Thomas, J. Karger-Kocsis, Thermal and crystallisation behaviours of blends of polyamide 12 with styrene-ethylene/butylene-styrene rubbers, Polymer 47 (2006) 6328-6336, http://dx.doi.org/10.1016/j.polymer.2006.07.002.

[33] K. Rinawa, S.N. Maiti, R. Sonnier, J.-M. Lopez-Cuesta, Non-isothermal crystallization kinetics and thermal behaviour of PA12/SEBS-g-MA blends, Bull. Mater. Sci. 38 (2015) 1315-1327, http://dx.doi.org/10.1007/s12034-015-1016-7.

[34] M. Du, B. Guo, D. Jia, Thermal stability and flame retardant effects of halloysite nanotubes on poly(propylene), Eur. Polym. J. 42 (2006) 1362-1369, http://dx. doi.org/10.1016/j.eurpolymj.2005.12.006.

[35] J.J. Huang, H. Keskkula, D.R. Paul, Rubber toughening of an amorphous polyamide by functionalized SEBS copolymers: morphology and Izod impact behavior, Polymer 45 (2004) 4203-4215, http://dx.doi.org/10.1016/j.polymer.2004.04.002.

[36] K. Prashantha, H. Schmitt, M.F. Lacrampe, P. Krawczak, Mechanical behaviour and essential work of fracture of halloysite nanotubes filled polyamide 6 nanocomposites, Compos. Sci. Technol. 71 (2011) 1859-1866, http://dx.doi.org/10.1016/j.compscitech.2011.08.019.

[37] K. Hedicke-Höchstötter, G.T. Lim, V. Altstädt, Novel polyamide nanocomposites based on silicate nanotubes of the mineral halloysite, Compos. Sci. Technol. 69 (2009) 330-334, http://dx.doi.org/10.1016/j.compscitech.2008.10.011.

[38] J.J. Huang, H. Keskkula, D.R. Paul, Comparison of the toughening behavior of nylon 6 versus an amorphous polyamide using various maleated elastomers, Polymer 47 (2006) 639-651, http://dx.doi.org/10.1016/j.polymer.2005.11.088.

[39] Y. Tang, S. Deng, L. Ye, C. Yang, Q. Yuan, J. Zhang, C. Zhao, Effects of unfolded and intercalated halloysites on mechanical properties of halloysite-epoxy nanocomposites, Compos. Part A Appl. Sci. Manuf. 42 (2011) 345-354, http://dx.doi.org/10.1016/j.compositesa.2010.12.003.

[40] B.J. Rashmi, Toughening of poly(lactic acid) without sacrificing stiffness and strength by melt-blending with polyamide 11 and selective localization of halloysite nanotubes, Express Polym. Lett. 9 (2015) 721-735, http://dx.doi.org/10.3144/expresspolymlett.2015.67.

[41] A.J. Oshinski, H. Keskkula, D.R. Paul, The effect of polyamide end-group configuration on morphology and toughness of blends with maleated elastomers, J. Appl. Polym. Sci. 61 (1996) 623-640, http://dx.doi.org/10.1002/(SICI)1097-4628(19960725)61:4<623::AID-APP6 > 3.3.CO;2-N. 